\title{
Nutrition for the Young Athlete
}

\author{
Francisco Jesús Llorente-Cantarero ${ }^{1}$ Laura Palomino-Fernández ${ }^{2}$ Mercedes Gil-Campos ${ }^{3}$
}

${ }^{1}$ Department of Artistic and Corporal Education, Faculty of Education, University of Cordoba, Cordoba, Spain

${ }^{2}$ Department of Paediatric, University of Córdoba, Córdoba, Spain

${ }^{3}$ Metabolism and Pediatric Research Unit, Reina Sofia University Hospital/Instituto Maimónides de Investigación Biomédica de Córdoba (IMIBIC), CIBERobn, University of Cordoba, Cordoba, Spain

J Child Sci 2018;8:e90-e98.
Address for correspondence Mercedes Gil-Campo, MD, PhD, Metabolism and Paediatric Research Unit, Reina Sofía University Hospital, Avda Menéndez Pidal s/n, 14004, Córdoba, Spain (e-mail: mercedes_gil_campos@yahoo.es).
Abstract
Keywords
- athletes
- children
- nutrition
- sport
- physical activity

Child athletes require a healthy and balanced nutrition according to the type and intensity of the sport activity. This review aims to provide integrated and updated information to establish adequate nutritional guidelines for these children, essentially avoiding deficiencies or unbalances that can be harmful for their health. A lack of vitamins and minerals can affect their health especially at long term and depending on the type of sport and age of the child. The diet must be controlled without any nutritional supplements. It is also important to know which nutrients can improve performance of the child athlete during both training and competition. In conclusion, the contribution of macro- and micronutrients to the diet, together with an adequate hydration according to the energy expenditure must be controlled for child athletes to ensure a good status of health.

\section{Introduction}

Currently, the demand for information about nutrition regarding physical activity (PA) has increased, not only in elite athletes, but also for all those people who regularly perform PA, including children. A proper nutrition can contribute to a better performance, avoid injuries, facilitate postexercise recovery, improve lifestyle habits, and maintain a good general health status and an adequate weight. ${ }^{1}$ It is therefore important that healthcare professionals have a good training and can help children who perform regular PA or any kind of sport to follow a diet which is tailored to their needs.

Physiological maturation and development processes that take place during childhood and adolescence must be well known to implement nutritional guidelines suitable to the age and intensity and type of exercise. These must be adjusted to the different stages of growth and development, avoiding the use of adult guidelines.

Nutrition in elite athletes usually requires a higher calorie intake, and special attention must be given to the intake of

received

June 29, 2018

accepted after revision July 1,2018
Issue Theme Nutrition in Child Health Conditions; Guest Editor: Pilar Codoñer Franch, MD, PhD. essential nutrients and micronutrients, due to the high rate of molecular replacement. In fact, there is evidence that nutritional intake is usually scarce regarding PA performed by most of the sports people, especially concerning minerals and vitamins. ${ }^{2-4}$ It is therefore necessary to inform the families of child athletes about the need to control their requirements to avoid both short- and long-term health issues.

The aim of this review is to describe and to analyze the nutritional needs of child athletes and the possible consequences on their health when there is a risk of nutritional imbalance, thus modifying the risk of developing disorders both during childhood adolescence and in later life.

\section{Energy Requirements}

The energy balance in a healthy individual is defined as the difference between the energy intake and the energy expenditure. If the balance is positive the excess will accumulate mainly as body fat. If, on the other hand, the balance is negative, it will lead to a decrease in body compartments. ${ }^{5}$ Different studies analyzing the loss of fat in relation to the
Copyright @ 2018 Georg Thieme Verlag KG Stuttgart · New York

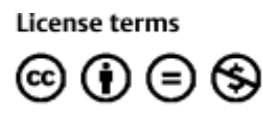


intensity of the physical performance ${ }^{6,7}$ observed that adiposity is only modified in high-performance PA, but it is not noticeable in situations of moderate intensity. Nevertheless, there are contradictory studies regarding fat distribution: while some authors have described an inverse relationship between fat at a central level and intense PA, ${ }^{8}$ and others, such as the AVENA study (Spanish acronym for Food and Assessment of the Nutritional Status of Adolescents), found no relation. ${ }^{9}$

The nutritional status of children is very vulnerable due to the high demand of nutrients related to the negative balance storage of body components. Excessive or insufficient changes in energy balance in children and adolescents can not only modify body composition, but also affect maturation and functional and structural tissue development. ${ }^{10}$

Energy requirements in children and adolescents are determined, in addition, by the energy needed to grow, which depends on the energy destined to synthesize fats and proteins that form tissues since the content of carbohydrates $(\mathrm{CH})$ of tissues is habitually insignificant. ${ }^{11}$

The recommendations for different intensity levels of PA must be accompanied by a good nutrition and vice versa. PA may account for around 25 to $30 \%$ of the total daily energy expenditure in a non-athletic individual and varies according to the level of PA. ${ }^{12}$ Moreover, this expenditure decreases because of growth and increases at the expense of PA from the first year onward, though subject to individual variability. ${ }^{13}$ Other factors such as the social environment of older children and adolescents have also been studied. Thus, rural societies reflect a greater energy expenditure and nutritional requirements in comparison with industrialized cities or countries. A reason for this could be that children who belong to rural or traditional societies start working at a very early age, either at home or outside it, whereas children in industrialized cities continue studying until a later age, thus consuming less energy. ${ }^{11}$

Therefore, there is a big difference in energy requirements between sedentary children and those whose level of exercise intensity is high for their age. This difference can be up to 15 times greater. $^{5}$

The maximum oxygen uptake $\left(\mathrm{VO}_{2} \mathrm{max}\right)$ objectively calculates the energy loss. This parameter must be measured individually for each activity. However, its implementation is not very extended since it is somewhat costly. $\mathrm{VO}_{2}$ increases in aerobic exercises until it reaches a stable rhythm, which happens before in children aged 10 to 11 years than in adults ${ }^{5}$ and depends on the activity level. ${ }^{12}$ In this way, the calorie expense in different sports can be assessed and it is going to depend on the body weigh. Palavecino ${ }^{12}$ found a big change between several sports after studied calories burned in 10 minutes of different sports practice, such as 34 cal for a person with $20 \mathrm{~kg}$ against $110 \mathrm{cal}$ of a person with $65 \mathrm{~kg}$, both after practicing volleyball.

\section{Nutrition Requirements}

Even though each nutrient has a particular effect on the sports performance, the nutritional requirements that child athletes present are generally influenced by the energy balance. On the other hand, the nutrition requirements are calculated for individuals with a normal body mass index (BMI) and can, therefore, vary in individuals with low weight, overweight, obesity, or a greater muscle development. To assess the average requirements in childhood and adolescence, three age groups must be considered: preschool children: (under 3 years old), schoolchildren (aged 3-10), and adolescents (aged 10-18). For each of these groups, the energy used for growth and the level of PA are considered (physical activity level [PAL]: 1.40, 1.58, and 1.75 , respectively). These values, associated to basal metabolism (for each age group, gender, size, and weight), are used to estimate the average requirements for each age group. Nevertheless, an individual can vary the PAL associated with their age group. In this case, the energy requirement will increase for children who perform 30 minutes of moderate PA for 5 or more days a week, 60 minutes of active sport five times a week or intense aerobic exercise associated to a competition sport in $0.15,0.3$, or 0.6 PAL units, respectively. $^{14}$

In addition, an inverse relation between PAL and percentage of body mass in young children and adolescents ${ }^{15}$ has been documented, especially in males. ${ }^{16}$ Thus, children with intense accumulated performance of 2 hours have shown a greater reduction in body fat levels than those with lower performance. ${ }^{17}$ A summary of macro and micronutrients and in which foods these are present are shown in - Table 1.

\section{Carbohydrates}

Especially during exercise, carbohydrates $(\mathrm{CH})$ are used as priority fuel, and fat burning takes a second place. The needs for $\mathrm{CH}$ have been related to the child's physical form, the type of training, the intensity, and duration of the exercise or nutritional status. ${ }^{18}$

In general, the use of $\mathrm{CH}$ increases with intensity and decreases with duration. Stored muscle glycogen and blood glucose are thus the main sources of energy through anaerobic glycolysis. As intensity decreases and duration increases, lipids become the main source of fuel through the aerobic system. Nonetheless, glucose is still of great importance, especially at the beginning of the activity and in the stages when oxygen supply does not meet the demands of the aerobic metabolism, such as endurance runs, which require an additional effort upon reaching the goal. ${ }^{10}$

One of the negative effects of extended exercise is hypoglycemia. It originates mainly at brain level and is independent of the energy substrates reserve available in the form of free fatty acids. The energy needs of the brain are satisfied almost exclusively through glucose. Its deficit manifests itself as fatigue, general malaise, inability to concentrate, lack of coordination, and even collapse. A good training helps athletes gradually acquire greater resistance to fatigue, which leads to achieving lower sensibility to hypoglycemia and the adaptation of the nervous system to this situation. Thus, energy is obtained in a sustainable way from blood lactate. The synthesis of lactate starts before reaching $\mathrm{VO}_{2 \text { max }}$. However, children have a lower ability to obtain energy from 
e92 Nutritional Guidelines for the Young Athlete Llorente-Cantarero et al.

Table 1. Macro and micronutrient content of several foods

\begin{tabular}{|c|c|}
\hline Nutrient & Food \\
\hline Fast absorption carbohydrates & Fruits, jelly, milk, and cake. \\
\hline Slow absorption carbohydrates & $\begin{array}{l}\text { Cereal and its products (flour, pasta, rice, bread, corn, and oats), legumes (chickpea, } \\
\text { bean, and lentil), and potatoes }\end{array}$ \\
\hline Fats & Olive oil or other vegetable oil (less palm oil or coconut oil), oily fish, and nuts \\
\hline Proteins & Fish, meats, milk, egg, and soya bean \\
\hline Vitamin A (retinol) & Orange and green vegetables, liver, and milk \\
\hline Vitamin $\mathrm{B}_{1}$ (thiamine) & Lean meat, liver, and whole wheat \\
\hline Vitamin $B_{2}$ (riboflavin) & Milk and its products, legumes, cereals, meats, and vegetable \\
\hline Vitamin $B_{3}$ (niacin) & Legumes, whole wheat, fish, and liver \\
\hline Vitamin $B_{5}$ (pantothenic acid) & Egg, milk and its products, legumes. \\
\hline Vitamin $\mathrm{B}_{6}$ (pyridoxine) & Fish, lean meat, and whole wheat \\
\hline Vitamin $B_{8}$ (biotin) & Legumes, fresh vegetables, nuts, dried fruits, meat, liver, and yolk \\
\hline Vitamin $B_{9}$ (folic acid) & Legumes, whole wheat, green leafy vegetables, nuts, orange, banana, and dried fruits \\
\hline Vitamin $\mathrm{B}_{12}$ (cyanocobalamin) & Meat, fish, and yolk \\
\hline Vitamin C (ascorbic acid) & Strawberry, citric fruit, kiwi, tomatoes, pepper, and green leafy vegetables \\
\hline Vitamin D (calciferol) & Oily fish, liver, and milk \\
\hline Vitamin E (tocopherol) & Nuts, vegetables oil, and green leafy vegetables \\
\hline Vitamin K (phylloquinine) & Green leafy vegetables, liver, and yolk \\
\hline Calcium & Milk and its products and dried legumes \\
\hline Phosphorus & Milk and its products, fish, meat, dried fruits, and whole wheat \\
\hline Potassium & Fruits, vegetables, milk, fish, and meat \\
\hline Sodium & Salt, salted food, milk, and cheese \\
\hline Magnesium & Whole wheat, nuts, and green leafy vegetables \\
\hline Iron & Meat, fish, seafood, meat, egg, legumes, and whole wheat \\
\hline Zinc & Meat fish, whole wheat, and seafood \\
\hline Fluorine & Tea and seafood \\
\hline Selenium & Fish, whole wheat, and meat \\
\hline Copper & Fish and meat \\
\hline lodine & Fish, seafood, and algae \\
\hline Chrome & Fat, vegetable oils, and meat \\
\hline
\end{tabular}

lactate, which leads to a lower accumulation of lactate and consequently less fatigue. Therefore, they can work out for a longer period but at a lower intensity. ${ }^{5}$

It is necessary for children to have suitable glycogen reserves to face prolonged exercise, especially when the duration of the PA exceeds75 minutes. The appearance of exhaustion will depend on $\mathrm{CH}$ richness of the diet. It has been observed that a diet rich in $\mathrm{CH}$ is critical to maintain the performance in both training and competition, ${ }^{19,20}$ although this issue has not been described in detail for adolescents and children. This has led to the so-called supra-compensation, according to which the athlete can reach the maximum levels of muscle glycogen, thus increasing the time of exercise until reaching exhaustion. ${ }^{21}$ For example, drinking a beverage containing $6 \%$ of glucose can provide the proper amount of $\mathrm{CH}$, improving the performance of cyclists. ${ }^{22}$
In this way, the necessary $\mathrm{CH}$ (dietary reference intakes [DRIs]) in a child with normal PA will be approximately 50 to $55 \%$, which corresponds to 6 to $10 \mathrm{~g} / \mathrm{kg}^{23}$ It must be ensured that at least half of the calorie intake of children who practice high-performance sports comes from $\mathrm{CH}$, and it should be spaced during the day. In the case of very intense exercise, the total intake must increase up to $70 \%$.

The suitable intake of $\mathrm{CH}$ is especially relevant in the competition day, when it is necessary to reinforce the deposits of muscle glycogen in the previous hours and during exercise to ensure a correct performance during the whole duration of the activity, especially if it lasts longer than an hour. Once the activity concludes, the athlete must have a meal which avoids post-exercise muscle catabolysis. Thus, the athlete will need $4 \mathrm{~g} / \mathrm{kg}$ of $\mathrm{CH}$ in the 3 to 4 hours before the sports activity, 0.5 to $1 \mathrm{~g} / \mathrm{kg}$ the previous hour, $0.7 \mathrm{~g} / \mathrm{kg}$ 
every hour distributed every 15 to 20 minutes during the activity, and 1 to $1.5 \mathrm{~g} / \mathrm{kg}$ after it. ${ }^{24}$

\section{Fats}

As previously mentioned, fats are the suitable fuel for lowintensity and long-duration activities. Physical exercise can lead to an increase in the use of fats and their mobilization. On the one hand, the oxidation of lipids in the form of freefatty acids increases within the muscle cell mitochondria reducing their concentration inside the cell which in turn stimulates the flow of free-fatty acids into the blood. This fact is due to the increase in adrenaline and noradrenaline during exercise that stimulates lipolysis. Other mechanisms are the decrease in circulating insulin and the increase in the activity of the central nervous system. Due to their complexity, these processes are very slow. About 20 to 30 minutes after starting the exercise, the function of the free-fatty acids begins to be activated, and they become available for a long period. It has not been proved that additional supplements of fatty products could improve performance in sport activities, since the body fat deposits are enough to balance out the needs. ${ }^{10}$

A beneficial effect of poly-unsaturated fatty acids (PUFAs) has also been suggested (especially omega-3) due to the increase in the synthesis of eicosanoids and anti-inflammatory cytokines. The British Nutrition Foundation recommends a total daily intake of 3 to $5.5 \mathrm{~g}$ PUFAs, considering that a higher intake will not influence performance or inflammation and immunity. On the other hand, an excessive and imbalanced intake of PUFAs might compromise the athlete's health due to the oxidative stress produced, which can exceed the antioxidant mechanisms. ${ }^{25}$ To prevent this situation, the intake of oil rich in oleic acid (extra virgin olive oil) is recommended as the main source of fat, since it protects the membranes from lipid peroxidation providing antioxidants and keeping a correct ratio of omega-6/omega3 (in general, $4: 1$ ). ${ }^{26}$

Carnitine is another supplement which is currently used to improve sports performance. Its use is based upon the fact that it optimizes the metabolism and use of fats. However, it has not been proved whether its regular intake improves performance during high-intensity anaerobic exercise or whether it influences the accumulation of lactic in this type of exercise. It is important to point out that, although L-carnitine is a safe supplement, D-carnitine can have toxic effects. ${ }^{27}$

Thus, the DRI of fats both in sedentary children and children who do high-performance exercise are similar. In general, 25 to $35 \%$ of calorie intake in children aged 1 to 18 should come from fats. Less than $10 \%$ of fatty acids consumed must be saturated and up to $10 \%$ must be polyunsaturated, and from these, 1 to $2 \%$ must come from linoleic acids. Moreover, 10 to $15 \%$ must be monounsaturated, with a maximum input of daily cholesterol of $300 \mathrm{mg} .^{28}$

\section{Proteins}

Energy from amino acids can be supplied through the diet or by the endogenous degradation of proteins in muscles. Given that the organism uses the diet $\mathrm{CH}$ before prolonged exercise, the main source of amino acids used afterward comes from the degradation of muscle proteins. Around 10 to $15 \%$ of the energy can be provided in this way.

Currently, the effects of the intensity and duration of exercise on the synthesis and degradation of proteins are uncertain. Exercise leads to a decrease in protein biosynthesis in muscle and liver, linked to an increase in its degradation. ${ }^{10}$

Only some foods contain proteins of high biological value with the presence of essential amino acids. These foods are proteins of animal origin, especially eggs and, to a lesser extent, beef and chicken, fish, and cow milk. Moreover, they present a greater digestibility than those derived from plant origin which, despite lacking some amino acids, are rich in methionine and lysine. If deficit of some of essential amino acids occurs, there is a degradation of other proteins to compensate which can decrease the strength and resistance of the individual to exercise.

In consequence, protein intake is essential for growth and intense exercise or high-stress situations. Proteins are responsible for muscle synthesis and repair and must provide 10 to $15 \%$ of the calories in a diet. Current recommendations (DRI) are equal for both sexes: $1.1 \mathrm{~g} / \mathrm{kg} /$ day for children aged 1 to 3, decreasing to $0.95 \mathrm{~g} / \mathrm{kg} /$ day until adolescence. The Recommended Dietary Allowances (RDA) for adolescents aged 16 to 19 should be reduced to $0.85 \mathrm{~g} / \mathrm{kg} / \mathrm{day}^{28}$ In addition, protein intake after sport activity should be 0.2 to $0.4 \mathrm{~g} / \mathrm{kg}^{24}$ An excessive protein intake does not increase muscle mass, but can rather contribute to increasing the fat compartment, since the amino acid deposit is not modifiable. In addition, it can increase the risk of health issues resulting from a diet lacking other nutrients.

However, the intake of proteins related to the intake of $\mathrm{CH}$ as useful nutrients in the recovery process should be considered. They must be consumed within 30 minutes after exercise and, again, within the next 2 hours to help restore glycogen and allow muscles to recover. ${ }^{29,30}$

\section{Vitamins}

An inadequate diet that do not meets the requirements of macro- and, especially, micronutrients can lead to a decrease in the performance of the child athlete. Even if the diet is rich in macronutrients, the input of vitamins and minerals could be incorrect. ${ }^{31}$ Correcting these dietary errors and supplying the adequate micronutrients would avoid the use of vitamin supplements which many athletes take and that does not significantly improve performance during exercise.

Water-soluble vitamins, specifically B vitamins such as $B_{1}$, $B_{6}$, niacin and folic acid are essential for certain metabolic systems of the organism. Thus, vitamin B could enhance the Krebs cycle. Vitamin $\mathrm{B}_{6}$ is closely linked to metabolic processes involving amino acids. Niacin plays a fundamental role in the electron transport chain. Folic acid participates in nucleic acid metabolism. Indeed, it is currently being debated whether there is a need to provide these vitamins as supplements. These vitamins can be supplied through the daily intake of fresh fruits and vegetables or through amino acid supplements ${ }^{10}$ in the case of certain athletes. 
Among lipid-soluble vitamins, vitamin D is the most outstanding. The role of this vitamin, nowadays considered as a hormone, is essential for the metabolism of the skeletal system, and suitable levels have been associated to injury prevention, better neuromuscular function, increase in type II fibers, lower inflammation, and lower risk of stress fractures. Current recommendations of vitamin D intake are $600 \mathrm{IU} /$ day for children aged between 4 and 18 years. ${ }^{32}$ The normal values of vitamin D also vary depending on geographic location and race. Athletes living in northern latitudes or those who train indoors (for example, figure skaters, gymnasts, and dancers) have a greater probability of suffering from a lack of vitamin D. ${ }^{29}$ This has also been observed in a study conducted with swimmers aged 18 to 30 years. Swimmers who train outdoors do have a higher mineral density and vitamin $\mathrm{D}$ level than those who train indoors. ${ }^{33}$ It is therefore essential to ensure a sufficient sunlight exposure. If supplements are used, these must be recommended by healthcare professionals, who must consider side effects of toxic levels, such as hypercalcemia and nephrocalcinosis.

\section{Minerals: Iron, Calcium, and Magnesium}

Regarding minerals iron, calcium, and magnesium deserve a special mention. Lower serum iron and decreased ferritin levels have been observed in endurance athletes, which can lead to anemia in these children. ${ }^{10}$ This situation involves a reduction in oxygen uptake and in the elimination of carbon dioxide that implies a decrease in muscle $\mathrm{pH}$ and therefore the alteration of metabolic processes in skeletal muscle. Moreover, a drop in the number of erythrocytes causes lower blood viscosity and results in a higher cardiac output. Additionally, intense exercise seems to increase plasma transferrin, which delays the release of iron. For these reasons, it is recommended to assess the iron levels, especially from adolescence onward and mainly in girls with abundant bleeding during menstruation to supply iron if needed. ${ }^{34}$ This control is also important in any athlete with a poor diet. During childhood and adolescence, it is mandatory to maintain adequate blood iron levels to ensure growth and the rise in blood volume and lean muscle mass. ${ }^{35}$ Children aged between 9 and 13 years must ingest 8 $\mathrm{mg} /$ day to avoid depletion in their iron reserves and iron deficiency anemia. Adolescents aged between 14 and 18 years require a higher amount of iron, up to $11 \mathrm{mg} /$ day for males and $15 \mathrm{mg} /$ day for females. ${ }^{36}$

Calcium requirements in athlete children and adolescents are higher than in sedentary children during development. On the other hand, excessive PA can cause bone decalcification affecting growth. Female athletes are more prone to amenorrhea, which leads to loss of bone mass resulting in increased fracture incidence. A correct intake of calcium and vitamin $D$, even in the form of supplements, is recommended to avoid a decrease in bone mass. Nevertheless, ensuring the intake of dairy products, which can be low in fat, is the most adequate measure. Calcium deficit can trigger muscle cramps, which can be avoided by slightly increasing the intake of this mineral (100-150 mg). The reference daily calcium intake is $1000 \mathrm{mg} /$ day for children aged between 4 and 8 years and $1300 \mathrm{mg} /$ day for children aged 9 and 11 years. ${ }^{37}$

Magnesium intake is important in sports involving weight restrictions, such as ballet or gymnastics. During and after exercise, there is usually a great loss of this mineral, especially in anaerobic sports and in prolonged events at high temperatures increasing through perspiration. It was observed that the magnesium intake was lower than the recommended daily intake whereas the relation calcium/ magnesium was greater in a study conducted with elite basketball, handball, and volleyball players. Directly proportional associations were also observed between magnesium intake and performance tests involving jumps and variables of isokinetic strength (extension and flexing). ${ }^{38}$

Nowadays there is an increase in the use of supplements among young. They claim to enhance health (to avoid deficits, anemia, and osteoporosis) or to improve performance. Currently, multivitamins associated to the so-called 'ergogenic aids' (such as creatinine or caffeine) are the most consumed. ${ }^{39,40}$ Their use is generalized despite the fact that studies have not proven that they enhance performance. ${ }^{41}$ Although the use of vitamins and minerals, as previously mentioned, is not necessarily dangerous; if consumed in excess, some of them may result toxic especially if they react with other nutrients. ${ }^{42}$ Besides, some of the commercial preparations associate other molecules, such as steroids, ${ }^{40}$ or they contain doses that have not been proven to affect health. ${ }^{43}$ The nutritional component of the training program of young athletes is especially important since there are many connections among nutritional deficiencies, growth, development, sports performance, and injury prevention. ${ }^{19}$ Nonetheless, research on the qualities of supplements in adolescent athletes aged under $18^{41}$ is very scarce. During the developmental stages, many physiological changes take in place, it is therefore very difficult to specify the consequences and possible side effects of a regular intake of vitamin supplements. ${ }^{39}$ Most studies have proven that athletes tend to have a greater control over the intake of healthy foods and therefore would not need a greater input of vitamins and minerals although we must be alert to the risk of associated deficiencies. ${ }^{19,31}$

\section{Hydration}

Perspiration during exercise leads to a loss of liquid that not only decreases performance, but can also affect health directly. Restoring liquids during exercise is therefore crucial. The goal is to choose the right moment for them to be absorbed as quickly as possible. The variable which determines liquid absorption to a greater extent is gastric emptying, which increases as the amount of liquid consumed increases up to a maximum of $600 \mathrm{~mL}$, when it becomes stable. This variable is the same both for a person at rest and one who performs moderate exercise, whereas in a person who does intense exercise the emptying is reduced altering rehydration. Moreover, liquid absorption also depends on the type of movement performed and the amount of liquid consumed. The composition of the liquid ingested is another factor to be considered. Active glucose and sodium transport, passive potassium transport, and 
neutralization of some acids accelerate water absorption. Furthermore, not all $\mathrm{CH}$ are absorbed in the same amount: maltose is absorbed best; fructose does not use active sodium transport; thus, its absorption is slower. ${ }^{10}$ In addition, the intake of fats slows down the emptying and therefore interferes the rehydration.

Taking into account the exercise duration and intensity, the American College of Sports Medicine (ACSM) and the Canadian Pediatric Society recommend how liquid should be

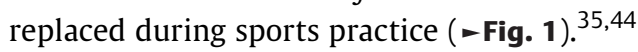

The intake of liquids containing sodium after exercise helps rehydration by stimulating thirst and liquid retention. Nonathletic individuals should avoid a regular intake of sports drinks containing $\mathrm{CH}$ since they can lead to an excessive calorie intake, increasing the risk of overweight, and tooth decay. ${ }^{27}$

\section{Nutrition and Physical Activity: Influence on Child's Health Status}

\section{Bone Compartment}

Exercise can reduce the risk of fractures through the increase of bone mass accumulated during growth. This period is the best moment to increase the mineral bone mass up to 15 to $30 \%$. Studies performed with tennis players suggest that exercise can increase periosteal apposition, which increases both bone diameter and strength. ${ }^{45}$ Nevertheless, a poor nutritional intake can lead to a greater amount of fractures due to calcium deficit or a higher risk of osteoporosis due to having failed to reach the peak of bone mineralization by the age of 30 . An increase in exercise in prepubertal girls elicited greater bone mineral gains at a range of skeletal sites compared with postmenarche girls, because pubertal growth spurt is the moment when bones are more receptive to the benefits of mechanical strain. ${ }^{46,47}$
The type of sport performed affects the bone mineral change. In sports which involve jumping, such as basketball, bone mass increases in the lumbar spine and the proximal femur since they are subject to a greater impact. ${ }^{48}$ However, in activities which do not involve weight bearing, such as cycling ${ }^{49}$ or swimming, ${ }^{33}$ no increase in bone mineral density was observed as compared with sedentary individuals, and it is lower than athletes who perform exercise involving weight bearing. $46,47,50,51$

\section{Development and Growth}

Sexual maturation can be delayed by the practice of highperformance sports given that it causes a delay in the transformation of dehydroepiandrosterone (DHEA) in testosterone. Thus, very intense exercise elicits an alteration in the adrenal-hypothalamus-hypophysis axis increasing the elimination of DHEA. Indeed, the individual may have adapted to training and requires a lower amount of DHEA in the organism to face it. ${ }^{52}$

On the other hand, there exist menstrual changes among elite athletes which can be associated to the so-called "female athlete triad." This triad was described for the first time in the early 90s and includes amenorrhea, low energy availability with or without eating disorders, and osteoporosis. ${ }^{53}$ This triad is clearly documented in the practice of certain sports such as rhythmic gymnastics. However, it is not fully verified in other sports such as swimming and volleyball. ${ }^{54}$ An inadequate hydration and an imbalanced diet might be possible causes of these menstrual disorders, although there are no studies which confirm these hypotheses.

Many girls and women athletes present hormonal disorders, such as hypoestrogenism, that play an essential role in the reduction of bone mineral density. In addition, amenorrhea produces a decrease in the markers of bone

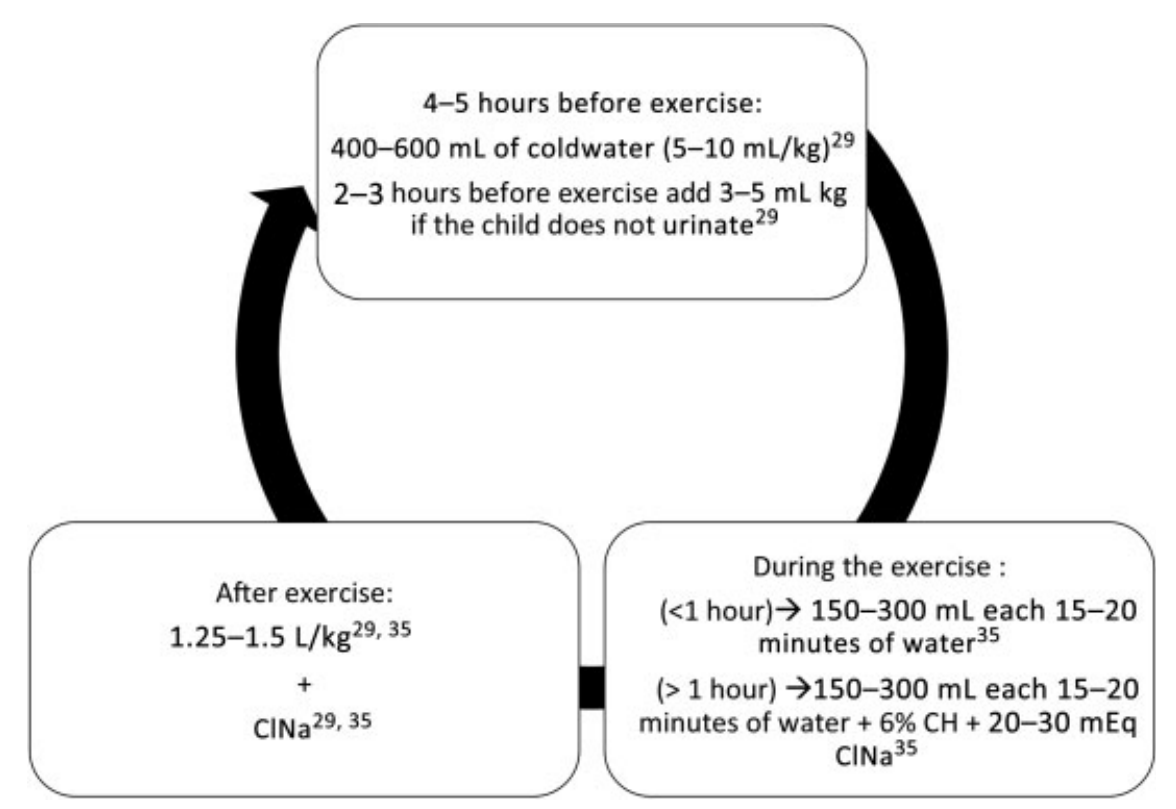

Fig. 1 Guidelines for proper hydration in sports activity. 
remodeling compared with athletes with regular cycles. ${ }^{46}$ Regarding growth, malnutrition caused by an incorrect nutrient intake regarding the level of PA alters the growth hormone $(\mathrm{GH})$ axis. The insulin-like growth factor (IGF-I) is reduced and peripheral resistance to the $\mathrm{GH}$ ends up slowing down growth. However, with a correct nutrition intake, sports (especially those involving stretching, such as basketball or volleyball) help to achieve an optimum growth.

Leptin is a hormone synthesized in the adipose tissue that plays an essential role in bone metabolism. It is considered a protective factor of osteoporotic fractures because it stimulates the proliferation of osteoblasts and inhibits the proliferation of adipocytes. Prolonged physical exercise reduces the levels of leptin whereas short exercise cycles do not modify its levels. ${ }^{46}$ However, resistance to the action of this hormone can occur at central level, and it has been described in obese children. ${ }^{55}$

\section{Factors Affecting the Performance of Physical Activity}

It is currently accepted that PA is beneficial for children of any age. However, one must be careful while recommending specific sports since they may exceed the physical abilities of children depending on their age. In the age range of 2 to 5 years, an important change takes place in the whole organism, body composition, organ size and maturation, and in the skeletal-muscle system. Moreover, it is the beginning of a period of integration of functions such as vision, proprioception, and the vestibular system. Therefore, during this age range, children must perform activities that help improve and reinforce these abilities, for example running or throwing objects and avoiding, where possible, competition with other children to ward off frustration. From 6 to 9 years, the competences acquired in the previous stage continue to improve, and abilities start to combine. The aim is therefore to perform activities that allow children to improve these new abilities, introducing a minimum competition between pairs, such as swimming, cycling, and football. From 10 to 12 years old, girls' and boys' organisms start to differ, but they can still compete against each other. Certain children of this age range already master complex motor activities. In addition, there is a greater understanding of strategy, and sports involving it are recommended. Pubertal development appears in early adolescence (13-15 years) and can make children stand out in a specific sport. Boys who develop earlier are taller and stronger than most children of their age, which gives them an advantage in sports like basketball or ice-hockey, or girls who develop later have narrower shoulders that make gymnastics easier. The recommendation of a specific PA must be determined both by the level of psychomotor and physical development and by the extent to which children enjoy it, which depends on several factors-family and educational environment and coaches.

Personal relationships, both social and in the school setting, stand out among the factors affecting eating habits and PA. At a preschool level family cohesion, parental influence and control are related in a positive way, even though no results were found in the relationship between PA and eating habits. At a school level, the socioeconomic status of teachers has been associated to a greater sports practice. Regarding eating habits, no school factor seems to affect them. ${ }^{56}$

The child's environment, the appearance of the neighborhood, the availability of sports centers, and how easy these are to access have shown a positive correlation with PA. Among social factors, it can be highlighted that the culture of PA has a positive relation with regular PA, and, on the contrary, sedentary practices relate to inadequate eating habits. $^{56}$

Nonetheless, there are differences between schoolchildren and adolescents regarding sports habits. While adolescents find their parents' socioeconomic status more important, schoolchildren place more importance on their parents' participation in the activity to achieve a greater adherence to its performance. ${ }^{56}$

Other studies have related PA and nutrition to age, sex, BMI, and other sociodemographic factors. Boys and girls aged 5 have the same probability of exercising, whereas from 6 to 7 years onward, PA decreases in girls while it remains steady in boys. This calls for an earlier introduction to sports in girls to avoid overweight and obesity. ${ }^{57-59}$ Regarding nutrition, as children get older, there is a greater probability of following correct guidelines for fruit and vegetable intake but also a greater probability of consuming sugary drinks. ${ }^{60,61}$ Other factors, such as parents' university education, lead to a better nutrition although it does not significantly increase the intake of fruits and vegetables. ${ }^{62,63}$

\section{Conclusion}

An adequate nutrition together with moderate-intense PA according to age is essential to maintain the child and adolescent's health and an optimum performance. To achieve it, an adequate intake of $\mathrm{CH}$, adapted to the type and level of activity, age, and weight is fundamental, as is drinking isotonic beverages drinks rich in $\mathrm{CH}$ to replenish them during exercise. It is also important to increase their intake in the days prior to competition in the correct way. Regarding fats, the other energy source, children of the same age and weight who exercise and those who do not exercise regularly should consume approximately the same amount. However, the first should avoid fat intake before competition PA since they slow down digestion and therefore affect performance. Proteins should be consumed in a low quantity with every meal, combined with other types of foods, since they are not a primary source of energy. As the duration of exercise increases, proteins contribute to hepatic gluconeogenesis and to maintain muscle mass. The intake of dairy products is vital since they supply essential nutrients, such as calcium and potassium, to achieve an optimum performance. Nutrition must go hand in hand with a correct electrolyte balance during exercise. Hydration must begin during the hours prior to exercise and continue always after finishing. 
Young athletes must be aware of the fact that what they eat is almost as important as when they eat it. General guidelines are as follows:

- To eat at least 3 hours before any sporting event to allow digestion and to ensure that it does not interfere with the competition. These meals must include the three main macronutrients: $\mathrm{CH}$ and proteins, fats in limited amount, and fibers.

- In the event of early morning competitions or training, it is recommended to drink liquids 1 to 2 hours prior to exercise and to have a complete breakfast once the activity is over. If the activity has a long duration, it is recommended to eat fresh foods and foods rich in $\mathrm{CH}$, which can also contribute to a correct hydration.

\section{Conflict of Interest}

None.

\section{References}

1 Palacios N, Montalvo Z, Ribas AM. Alimentación, nutrición e hidratación en el deporte. Madrid: Consejo Superior de Deportes, Ministerio de Educación, Política Social y Deportes. Serv Med Endocrinol Nutr 2009. Available at: http://www.csd.gob.es/csd/estaticos/dep-salud/ guia-alimentacion-deporte.pdf. Accessed November, 2017

2 Eskici G, Ersoy G. An evaluation of wheelchair basketball players' nutritional status and nutritional knowledge levels. J Sports Med Phys Fitness 2016;56(03):259-268

3 Hosseinzadeh J, Maghsoudi Z, Abbasi B, Daneshvar P, Hojjati A, Ghiasvand R. Evaluation of dietary intakes, body composition, and cardiometabolic parameters in adolescent team sports elite athletes: a cross-sectional study. Adv Biomed Res 2017;6:107

4 Papadopoulou SK, Papadopoulou SD, Gallos GK. Macro- and micro-nutrient intake of adolescent Greek female volleyball players. Int J Sport Nutr Exerc Metab 2002;12(01):73-80

5 Redondo C, González M, Moreno L, García M. Actividad física, deporte, ejercicio y salud en niños y adolescentes. Assoc Esp Pediatr 2010;xx:1-208

6 Ruiz JR, Rizzo NS, Hurtig-Wennlöf A, Ortega FB, Wärnberg J, Sjöström M. Relations of total physical activity and intensity to fitness and fatness in children: the European Youth Heart Study. Am J Clin Nutr 2006;84(02):299-303

7 Metcalf BS, Voss LD, Hosking J, Jeffery AN, Wilkin TJ. Physical activity at the government-recommended level and obesityrelated health outcomes: a longitudinal study (Early Bird 37). Arch Dis Child 2008;93(09):772-777

8 Platat C, Wagner A, Klumpp T, Schweitzer B, Simon C. Relationships of physical activity with metabolic syndrome features and low-grade inflammation in adolescents. Diabetologia 2006;49 (09):2078-2085

9 Ortega FB, Tresaco B, Ruiz JR, et al; AVENA Study Group. Cardiorespiratory fitness and sedentary activities are associated with adiposity in adolescents. Obesity (Silver Spring) 2007;15(06): 1589-1599

10 Gil A. Tratado de Nutrición. Nutrición humana en el estado de salud. Madrid: Editorial Medica Panamericana; 2017

11 Torun B. Energy requirements of children and adolescents. Public Health Nutr 2005;8(7A):968-993

12 Palavecino N. Nutrición para el alto rendimiento: Libros en Red; 2002. Available at: http://pilarmartinescudero.es/EneroFebreroMarzo2014/nutricion\%20para\%20el\%20alto\%20rendimiento.pdf. Accessed February, 2018

13 Wells JC, Davies PS. Estimation of the energy cost of physical activity in infancy. Arch Dis Child 1998;78(02):131-136
14 Millward DJ. A new approach to establishing dietary energy reference values. Curr Opin Clin Nutr Metab Care 2012;15(05): 413-417

15 Ekelund U, Aman J, Yngve A, Renman C, Westerterp K, Sjöström M. Physical activity but not energy expenditure is reduced in obese adolescents: a case-control study. Am J Clin Nutr 2002;76(05): 935-941

16 Ball EJ, O'Connor J, Abbott R, et al. Total energy expenditure, body fatness, and physical activity in children aged 6-9 y. Am J Clin Nutr 2001;74(04):524-528

17 Abbott RA, Davies PS. Habitual physical activity and physical activity intensity: their relation to body composition in 5.0-10.5y-old children. Eur J Clin Nutr 2004;58(02):285-291

18 Sánchez-Valverde Visus F, Moráis López A, Ibáñez J, Dalmau Serra J; Comité de Nutrición de la Asociación Española de Pediatría [Nutrition recommendations for children who practice sports]. An Pediatr (Barc) 2014;(02):125.e1-e126. doi: 10.1016/j.anpedi.2013.08.007

19 Petrie HJ, Stover EA, Horswill CA. Nutritional concerns for the child and adolescent competitor. Nutrition 2004;20(7-8):620-631

20 Rosenbloom CA, Loucks AB, Ekblom B. Special populations: the female player and the youth player. J Sports Sci 2006;24(07): 783-793

21 Delgado M, Castillo MJ, Gutiérrez A. Entrenamiento físico-deportivo y alimentación. Paidotribo;2016

22 Hottenrott K, Hass E, Kraus M, Neumann G, Steiner M, Knechtle B. A scientific nutrition strategy improves time trial performance by $\approx 6 \%$ when compared with a self-chosen nutrition strategy in trained cyclists: a randomized cross-over study. Appl Physiol Nutr Metab 2012;37(04):637-645

23 Rodriguez NR, DiMarco NM, Langley S; American Dietetic Association; Dietitians of Canada; American College of Sports Medicine: Nutrition and Athletic Performance. Position of the American Dietetic Association, Dietitians of Canada, and the American College of Sports Medicine: Nutrition and athletic performance. J Am Diet Assoc 2009;109(03):509-527

24 Kleinman R. American Academy of Pediatrics. Committee on nutrition. Pediatric Nutrition Handbook. Elk Grove Village: American Academy of Pediatrics; 2009

25 Pingitore A, Lima GP, Mastorci F, Quinones A, Iervasi G, Vassalle C. Exercise and oxidative stress: potential effects of antioxidant dietary strategies in sports. Nutrition 2015;31(7-8):916-922

26 Simopoulos AP. The importance of the ratio of omega-6/omega-3 essential fatty acids. Biomed Pharmacother 2002;56(08):365-379

27 Committee on Nutrition and the Council on Sports Medicine and Fitness. Sports drinks and energy drinks for children and adolescents: are they appropriate? Pediatrics 2011;127(06): 1182-1189

28 Institute of the Medicine. Dietary Reference Intakes for Energy, Carbohydrate, Fiber, Fat, Fatty Acids, Cholesterol, Protein, and Amino Acids. Washington, DC: National Academies Press; 2005

29 Position of Dietitians of Canada, the American Dietetic Association, and the American College of Sports Medicine: Nutrition and Athletic Performance. Can J Diet Pract Res 2000;61(04):176-192

30 Litt A. Fuel for Young Athletes: Essential Foods and Fluids for Future Champions. Windsor: Human Kinetics; 2004

31 Nikic M, Pedišic Ž, Šatalic Z, Jakovljevic S, Venus D. Adequacy of nutrient intakes in elite junior basketball players. Int J Sport Nutr Exerc Metab 2014;24(05):516-523

32 Institute of Medicine Dietary reference intakes for calcium and vitamin D. Consensus Report. 2010. Available at: www.iom.edu/ Reports/2010/Dietary-Reference-Intakes-for-Calcium-and-Vitamin-D.aspx. Accessed December, 2017

33 Gomez-Bruton A, Montero-Marín J, González-Agüero A, et al. Swimming and peak bone mineral density: asystematic review and meta-analysis. J Sports Sci 2018;36(04):365-377

34 Earl R, Woteki C. Iron Deficiency Anemia: Recommended Guidelines for the Prevention, Detection, and Management Among U.S. 
Children and Women of Childbearing Age. Washington DC: National Academy Press; 1993

35 Hoch AZ, Goossen K, Kretschmer T. Nutritional requirements of the child and teenage athlete. Phys Med Rehabil Clin N Am 2008; 19(02):373-398, $x$

36 Otten JJ, Hellwig JP, Meyers LD. Dietary Reference Intakes: The Essential Guide to Nutrient Requirements. The National Academies Press; 2006. Doi: https://doi.org/10.17226/11537

37 Purcell LK; Canadian Paediatric Society, Paediatric Sports and Exercise Medicine Section. Sport nutrition for young athletes. Paediatr Child Health 2013;18(04):200-205

38 Santos DA, Matias CN, Monteiro CP, et al. Magnesium intake is associated with strength performance in elite basketball, handball and volleyball players. Magnes Res 2011;24(04):215-219

39 Calfee R, Fadale P. Popular ergogenic drugs and supplements in young athletes. Pediatrics 2006;117(03):e577-e589

40 Metzl JD, Small E, Levine SR, Gershel JC. Creatine use among young athletes. Pediatrics 2001;108(02):421-425

41 Gomez J; American Academy of Pediatrics Committee on Sports Medicine and Fitness. Use of performance-enhancing substances. Pediatrics 2005;115(04):1103-1106

42 Maughan RJ, King DS, Lea T. Dietary supplements. J Sports Sci 2004;22(01):95-113

43 Clarkson P, Coleman E, Rosenbloom C. Risky dietary supplements. Sports Science Exchange Roundtable 48, 2002;1:1-4

44 American Dietetic Association. Position of the American dietetic association, dietitians of Canada, and the American college of sports medicine: nutrition and athletic performance. J Am Diet Assoc 2000;100(12):1543-1556

45 Bradney M, Pearce G, Naughton G, et al. Moderate exercise during growth in prepubertal boys: changes in bone mass, size, volumetric density, and bone strength: a controlled prospective study. J Bone Miner Res 1998;13(12):1814-1821

46 Muñoz MT, Barrios V, Garrido G, Argente J. Ejercicio físico y masa ósea en adolescentes deportistas. Rev Esp Pediatr 2003;59:61-69

47 Heinonen A, Sievänen H, Kannus P, Oja P, Pasanen M, Vuori I. Highimpact exercise and bones of growing girls: a 9-month controlled trial. Osteoporos Int 2000;11(12):1010-1017

48 Bagur-Calafat C, Farrerons-Minguella J, Girabent-Farrés M, SerraGrima JR. The impact of high level basketball competition, calcium intake, menses, and hormone levels in adolescent bone density: a three-year follow-up. J Sports Med Phys Fitness 2015;55(1-2):58-67

49 Olmedillas H, González-Agüero A, Moreno LA, Casajus JA, Vicente-Rodríguez G. Cycling and bone health: a systematic review. BMC Med 2012;10:168

50 Guadalupe-Grau A, Fuentes T, Guerra B, Calbet JA. Exercise and bone mass in adults. Sports Med 2009;39(06):439-468
51 Tenforde AS, Fredericson M. Influence of sports participation on bone health in the young athlete: a review of the literature. PM R 2011;3(09):861-867

52 Filaire E, Duché P, Lac G. Effects of amount of training on the saliva concentrations of cortisol, dehydroepiandrosterone and on the dehydroepiandrosterone: cortisol concentration ratio in women over 16 weeks of training. Eur J Appl Physiol Occup Physiol 1998; 78(05):466-471

53 Mountjoy M. Olympic Handbook of Sports Medicine: Handbook of Sports Medicine and Science, the Female Athlete: the Female Athlete (1). International Olympic Committee. Wiley-Blackwell; 2014

54 Stefani L, Galanti G, Lorini S, Beni G, Dei M, Maffulli N. Female athletes and menstrual disorders: a pilot study. Muscles Ligaments Tendons J 2016;6(02):183-187

55 Gil-Campos M, Aguilera CM, Ramírez-Tortosa MC, Cañete R, Gil A Fasting and postprandial relationships among plasma leptin, ghrelin, and insulin in prepubertal obese children. Clin Nutr 2010;29(01):54-59

56 de Vet E, de Ridder DT, de Wit JB. Environmental correlates of physical activity and dietary behaviours among young people: a systematic review of reviews. Obes Rev 2011;12(05): e130-e142

57 Kimm SY, Glynn NW, Kriska AM, et al. Decline in physical activity in black girls and white girls during adolescence. $\mathrm{N}$ Engl J Med 2002;347(10):709-715

58 Finn K, Johannsen N, Specker B. Factors associated with physical activity in preschool children. J Pediatr 2002;140(01):81-85

59 Hinkley T, Crawford D, Salmon J, Okely AD, Hesketh K. Preschool children and physical activity: a review of correlates. Am J Prev Med 2008;34(05):435-441

60 French SA, Lin BH, Guthrie JF. National trends in soft drink consumption among children and adolescents age 6 to 17 years: prevalence, amounts, and sources, 1977/1978 to 1994/1998. J Am Diet Assoc 2003;103(10):1326-1331

61 Kim SA, Moore LV, Galuska D, et al; Division of Nutrition, Physical Activity, and Obesity, National Center for Chronic Disease Prevention and Health Promotion, CDC. Vital signs: fruit and vegetable intake among children - United States, 2003-2010. Morb Mortal Wkly Rep 2014;63(31):671-676

62 Han E, Powell LM. Consumption patterns of sugar-sweetened beverages in the United States. J Acad Nutr Diet 2013;113(01): 43-53

63 Kunin-Batson AS, Seburg EM, Crain AL, et al. Household factors, family behavior patterns, and adherence to dietary and physical activity guidelines among children at risk for obesity. J Nutr Educ Behav 2015;47(03):206-215 